\title{
Evolution of the $\alpha_{2}$-adrenoreceptors in vertebrates: ADRA2D is absent in mammals and crocodiles
}

\author{
Héctor A. Céspedes ${ }^{1}$, Kattina Zavala ${ }^{1}$, Juan C. Opazo ${ }^{1,2}$ \\ ${ }^{1}$ Instituto de Ciencias Ambientales y Evolutivas, Facultad de Ciencias, \\ Universidad Austral de Chile, Valdivia, Chile. ${ }^{2}$ David Rockefeller Center For Latin \\ American Studies, Harvard University, MA, USA.
}

\author{
Corresponding author: \\ Juan C. Opazo \\ Instituto de Ciencias Ambientales y Evolutivas \\ Facultad de Ciencias \\ Universidad Austral de Chile \\ Valdivia, Chile
}

Email: jopazo@gmail.com

Phone: +56 632221674 


\begin{abstract}
Evolutionary studies of genes that have been functionally characterized and whose variation has been associated with pathological conditions represent an opportunity to understand the genetic basis of pathologies. $\alpha_{2}$-adrenoreceptors (ADRA2) are a class of $G$ protein-coupled receptors that regulate several physiological processes including blood pressure, platelet aggregation, insulin secretion, lipolysis, and neurotransmitter release. This gene family has been extensively studied from a molecular/physiological perspective, yet much less is known about its evolutionary history. Accordingly, the goal of this study was to investigate the evolutionary history of $\alpha_{2}$-adrenoreceptors (ADRA2) in vertebrates. Our results show that in addition to the three well-recognized $\alpha_{2}$-adrenoreceptor genes (ADRA2A, ADRA2B and ADRA2C), we recovered a clade that corresponds to the fourth member of the $\alpha_{2}$-adrenoreceptor gene family (ADRA2D). We also recovered a clade that possesses two ADRA2 sequences found in two lamprey species. Furthermore, our results show that mammals and crocodiles are characterized by possessing three $\alpha_{2}$-adrenoreceptor genes, whereas all other vertebrate groups possess the full repertoire of $\alpha_{2-}$ adrenoreceptor genes. Among vertebrates ADRA2D seems to be a dispensable gene, as it was lost two independent times during the evolutionary history of the group. Additionally, we found that most examined species possess the most common alleles described for humans; however, there are cases in which nonhuman mammals possess the alternative variant.
\end{abstract}

Keywords: ADRA2; gene family evolution; whole genome duplication; evolutionary medicine. 


\section{Introduction}

Evolutionary studies of gene families that have been functionally characterized and whose variation has been linked to pathological conditions in humans represent an opportunity to understand the genetic basis of pathologies. Comparative studies have revealed that non-model species harbor genetic variation that could be relevant to understanding the physiological function of molecules that play key roles in health and disease (Opazo et al. 2005; Albertson et al. 2009; Yu et al., 2011; Edrey et al., 2012; Henning et al., 2014; Faulkes et al., 2015; Wichmann et al. 2016; Zavala et al., 2017). Studies carried out in nonmodel species that are resistant to diseases that have caused a high number of human deaths have been particularly important (e.g. Alzheimer, cancer)(Gorbunova et al., 2012; Castro-Fuentes and Socas-Pérez, 2013; Manov et al., 2013; Henning et al., 2014; Braidy et al., 2015; Faulkes et al., 2015; Inestrosa et al., 2015).

Adrenoceptors are a class of $\mathrm{G}$ protein-coupled cell membrane receptors that are mediators in the sympathetic nervous system. They regulate physiological functions to maintain homeostasis by mediating the action of catecholamines such as epinephrine and norepinephrine. There are two groups of adrenergic receptors, $\alpha$ and $\beta$, and there are several subtypes in each group. Within the $\alpha$-type, the $\alpha_{2}$-adrenoreceptors (ADRA2) are composed of three subtypes: ADRA2A, ADRA2B and ADRA2C (Bylund et al., 1988). They are mainly expressed in the nervous system and platelets and regulate several key physiological processes including blood pressure, platelet aggregation, insulin secretion, lipolysis, and neurotransmitter release (Knaus et al. 2007). They also play significant roles during development as the deletion of the three $\alpha_{2}$ adrenoreceptor genes results in embryonic lethality (Philipp et al., 2002). At the individual level, the $\alpha_{2 A}$-adrenoreceptors (ADRA2A) mediate inhibition of insulin release (Gribble, 2010; Rosengren et al., 2010), hypotension, bradycardia, baroreceptor reflex sensitivity, sedation, and hypnosis (MacMillan et al., 1996; Lakhlani et al., 1997, Niederhoffer et al., 2004). The $\alpha_{2 B}$-adrenoreceptors (ADRA2B) play important roles in the regulation of vascular tone (Link et al., 
1996) as well as in the development of the placenta (Muthig et al., 2007) and lungs (Haubold et al., 2010). The $\alpha_{2 c}$-adrenoreceptors (ADRA2C) control the secretion of epinephrine via an autocrine feedback loop in the adrenal medulla (Brede et al., 2002, 2003; Gilsbach et al., 2007). In the past, a fourth type of ADRA2 receptor was described (ADRA2D) based on pharmacological assays (Bylund, 2005). This fourth type of receptor was initially identified in rat, mouse, and cow and was mainly characterized as having a low affinity for yohimbine and rauwolscine. However, subsequent studies have revealed that this receptor in these species would not be a fourth type of $\alpha_{2}$-adrenoreceptor; instead it would be an ADRA2A type of receptor with divergent pharmacological properties (Lanier et al., 1991; Link et al., 1992). Thus, $\alpha_{2}$-adrenoreceptor gene family is a group of cell membrane receptors that plays significant physiological roles from embryogenesis to adulthood that would be greatly benefited of having evolutionary information.

Accordingly, the main goal of this study was to unravel the evolutionary history of $\alpha_{2}$-adrenoreceptors (ADRA2) in vertebrates. To do so we annotated $\alpha_{2}-$ adrenoreceptor (ADRA2) genes in species representative of all main groups of vertebrates. Using phylogenetic and syntenic approaches, we defined the composition of the gene family, orthologous relationships within each family member, and patterns of differential retention. We also studied genetic variability in non-model species related to humans; specifically, we analyzed variability at sites known to have consequences in human health. Our results show that in addition to the three well-recognized $\alpha_{2}$-adrenoreceptor genes (ADRA2A, ADRA2B and ADRA2C), we recovered a clade that corresponds to the fourth member of the $\alpha_{2}$-adrenoreceptor gene family (ADRA2D). We also recovered a clade that possesses two $\alpha_{2}$-adrenoreceptor sequences found in two species of lampreys. Based on the phyletic distribution of the genes, we show that mammals and crocodiles are characterized by possessing three $\alpha_{2^{-}}$ adrenoreceptor genes, whereas all other vertebrate groups possess the full repertoire of four $\alpha_{2}$-adrenoreceptor genes. The most dispensable $\alpha_{2-}$ adrenoreceptor gene seems to be the ADRA2D gene as it was lost two 
independent times during the evolutionary history of vertebrates. We found that most examined species possess the most common alleles described for humans. There is a group of sites for which some species possess the most common allele, whereas others possess the alternative allele. There is one position for which the rare allele is present in all non-human species, and there are some cases in which novel alleles are present.

\section{Materials and methods}

\subsection{DNA data and phylogenetic analyses}

We used bioinformatic procedures to annotate $\alpha_{2}$-adrenoreceptor genes in species of all major groups of vertebrates. Our sampling included species from mammals, birds, reptiles, amphibians, coelacanths, teleost fish, holostean fish, cartilaginous fish and cyclostomes (Supplementary Table S1). We also included sequences of the dopamine receptors $D(D R D) 1,2,3,4$ and 5 , and $\beta$ adrenoreceptors (ADRB) 1, 2 and 3 from humans (Supplementary Table S1). Amino acid sequences were aligned using the FFT-NS-i strategy from MAFFT v.6 (Katoh and Standley, 2013). We used the proposed model tool of IQ-Tree (Trifinopoulos et al., 2016) to select the best-fitting model of amino acid substitution (JTT + R6). Phylogenetic relationships were estimated according to maximum likelihood approach. We performed a maximum likelihood analysis to obtain the best tree using the program IQ-Tree (Trifinopoulos et al., 2016) and assessed support for the nodes with 1,000 bootstrap pseudoreplicates using the ultrafast routine. Human ADRA1A, B, and D sequences were used as outgroups.

\subsection{Assessments of Conserved Synteny}

We examined genes found upstream and downstream of the $\alpha_{2}$-adrenoreceptor genes of species representative of all main groups of vertebrates. We used the estimates of orthology and paralogy derived from the EnsemblCompara database (Herrero et al., 2016); these estimates are obtained from an automated pipeline that considers both synteny and phylogeny to generate orthology mappings. These predictions were visualized using the program Genomicus 
v86.01 (Louis et al., 2015). Our analyses were performed in humans (Homo sapiens), opossum (Monodelphis domestica), chinese turtle (Pelodiscus sinensis), chicken (Gallus gallus), anole lizard (Anolis carolinensis), clawed frog (Xenopus tropicalis), coelacanth (Latimeria chalumnae), spotted gar (Lepisosteus oculatus) and elephant shark (Callorhinchus milii). In the case of the elephant shark (http://esharkgenome.imcb.a-star.edu.sg/), the genomic pieces containing $A D R A 2$ genes were annotated, and predicted genes were then compared with the non-redundant protein database using Basic Local Alignment Search Tool (BLAST) (Altschul et al., 1990).

\section{Results and discussion}

\subsection{Gene trees, synteny analyses, and orthology}

We constructed a phylogenetic tree in which we included ADRA2 sequences of representative species of all major groups of vertebrates. Our phylogenetic analyses recovered the monophyly of the ADRA2 sequences with strong support (Fig. 1). Within the ADRA2 clade, we recovered five monophyletic groups that correspond to the three already well characterized $\alpha_{2}$-adrenoreceptor genes (ADRA2A, ADRA2B and ADRA2C), a clade that correspond to the fourth member of the $\alpha_{2}$-adrenoreceptor gene family (ADRA2D), plus a clade that contains the ADRA2 sequences of two lamprey species (Fig. 1). It is important to note that the ADRA2D clade we identified in our phylogenetic analyses does not correspond to the clade that includes the $\alpha_{2}$-adrenoreceptor gene of rat, mouse and cow that in the past was named ADRA2D (Bohmann et al. 1994; Kobayashi et al. 2004; Bylund, 2005). The use of the name ADRA2D to refer to the clade including the $\alpha_{2}$-adrenoreceptor gene of rat, mouse, and cow was assigned based on pharmacological assays; specifically, lower affinity of yohimbine and rauwolscine for the receptor. Homology, however, is an evolutionary concept that is related but not based on functionality (Gabaldón, 2008; Gabaldón \& Koonin, 2013). Subsequent studies have revealed that what was called $\alpha_{2 D^{-}}$ adrenoreceptor (ADRA2D) in rat and mouse in actuality is not a fourth type of $\alpha_{2}-$ adrenoreceptor; instead it is an ortholog to the $\alpha_{2 A}$-adrenoreceptor (ADRA2A) of 
other mammals (Lanier et al., 1991; Link et al., 1992).

Within the ADRA2 clade, phylogenetic relationships among different members of the gene family are also well supported (Fig. 1). We recovered a monophyletic group containing the ADRA2A and lamprey clades, which in turn was recovered as sister to the ADRA2B sequences (Fig. 1). The monophyletic group including ADRA2C sequences was recovered as sister to the aforementioned clade (Fig.1), whereas the ADRA2D clade was recovered as sister to all other ADRA2 groups (Fig. 1). In agreement with previous results, the clade that includes dopamine receptors (DRD) 2, 3 and 4 was recovered as sister to the ADRA2 clade (Spielman et al., 2015; Zavala et al., 2017). Although we expected dopamine receptors (DRD) 1 and 5 to be sister to the $\beta$ adrenoreceptors (ADRB) (Spielman et al., 2015; Zavala et al., 2017), this was not the case. This could mainly be due to the fact that the sampling effort performed in this study was not aimed at resolving the evolutionary relationship among these genes. The synteny analyses gave further support for the identity of the four $\alpha_{2}$-adrenoreceptor clades identified for all of the main groups of gnathostomes (Fig. 2). Although we found variation in the pattern of conservation of genes found up- and downstream of the ADRA2 genes, in all cases it is possible to realize that each ADRA2 gene is located in a chromosomal location that is more or less conserved in all examined species (Fig. 2). For example, in the case of the ADRA2A gene, there are four upstream genes (SHOC2, BBIP1, PDCD4 and RBM20) and five downstream genes (GPAM, TECTB, ACSL5, ZDHHC6 and VTI1A) that are well conserved in most examined species (Fig. 2); this suggests that this gene arrangement was present in the common ancestor of the group between 615 and 473 million years ago and was inherited by all descendant lineages. It is worth noting that the genomic region where the ADRA2D gene is located is also conserved in species that lost the gene (e.g. humans; Fig. 2).

From the phylogenetic analyses it was possible to define orthology among the gnathostome sequences, however, this was not possible for the lamprey sequences (Fig. 1). Genome-wide compositional analyses have shown that 
lamprey genomes possess compositional bias (Qiu et al., 2011; Kuraku, 2013; Mehta et al., 2013; Smith et al., 2013) that makes it difficult to recover the true evolutionary history of genes using phylogenetic inference. In support of this idea, other studies working with different gene families have also observed that lamprey sequences tend to group together instead of with their true ortholog (Qiu et al., 2011; Nah et al., 2014; Campanini et al., 2015; Opazo et al., 2015; Wichmann et al., 2016; Zavala et al., 2017). In the case of the sea lamprey, we also explored the genomic piece in which we found the ADRA2 gene to determine if syntenic genes could be found that would help us to define orthology. In principle, if we found syntenic genes in lampreys that have a human ortholog located in one of the chromosomes where the ADRA2 genes are located, we could suggest orthology. In our analyses, we found two genes (RNF122 and C20orf27) on the 3' side of the sea lamprey ADRA2 gene; unfortunately, neither of these genes had an ortholog on a human chromosome where ADRA2 genes are located. The RNF122 gene is located on human chromosome 8, while C20orf27 is located on human chromosome 20.

\subsection{Diversification and differential retention of ADRA2 genes during the evolutionary history of vertebrates}

In this study we identified four types of $\alpha_{2}$-adrenoreceptors in species representative of all of the main groups of vertebrates (ADRA2A, ADRA2B, ADRA2C and ADRA2D; Fig. 1). The phyletic distribution of the $\alpha_{2^{-}}$ adrenoreceptors found here suggests that the last common ancestor of the group, which existed between 676 and 615 million years ago, possessed the full repertoire of $\alpha_{2}$-adrenoreceptors observed in extant species. However, given that the last common ancestor of vertebrates underwent two rounds of whole genome duplication (Ohno et al., 1968; Meyer and Schartl, 1999; McLysaght et al., 2002; Dehal and Boore, 2005; Hoegg and Meyer, 2005; Putnam et al., 2008), it is possible that at some point in time the vertebrate ancestor had just one ADRA2 gene, which after the two rounds of whole genome duplication gave rise to the actual repertoire of four genes. In support of this idea, the $\alpha_{2}$-adrenoreceptor 
gene family appears in the repository of genes that were retained after the whole genome duplications occurred in the vertebrate ancestor (Singh et al., 2015). This pattern of gene diversification has also been observed for other gene families (Blomme et al., 2006; Hoffmann and Opazo, 2011; Hoffmann et al., 2012; Storz et al., 2013; Wichmann et al., 2016; Zavala et al., 2017), highlighting the pivotal role of whole genome duplication in the origin of biological diversity.

After the repertoire of four $\alpha_{2}$-adrenoreceptor genes was established, vertebrate groups retained different complements of $\alpha_{2}$-adrenoreceptor genes (Fig. 3). According to our assessment, all but two groups retained the full complement of $\alpha_{2}$-adrenoreceptor genes (Fig. 3). Only mammals and crocodiles retained three family members (Fig. 3), and in both cases the lost gene was the $\mathrm{\alpha}_{2 \mathrm{D}}$-adrenoreceptor gene (ADRA2D; Fig. 3) which is likely a dispensable gene as it has been lost two independent times during the evolutionary history of vertebrates (Fig. 3). Based on the phyletic distribution of the $\alpha_{2}$-adrenoreceptor genes, it is possible to suggest that for mammals and crocodiles just having three members of the gene family is enough to maintain all biological functions associated with this group of genes. Likewise it is possible that there is some degree of redundancy that works as a backup (i.e. functionally overlapping paralogues) in the event that one of the genes is lost or inactivated (Gitelman, 2007; Cañestro et al., 2009; Félix \& Barkoulas, 2015; Albalat \& Cañestro, 2016). Thus, the differential retention of $\alpha_{2}$-adrenoreceptor genes could be seen as a stochastic process, in which the observed differences in gene repertoires do not necessarily translate into functional consequences. However, it is also possible that the retention of multiple (redundant) gene copies could help to direct the trajectory of physiological evolution by providing an increased opportunity for the origin of biological novelties (Ohno et al., 1968; Ohno, 1970; Force et al., 1999; Hughes, 1994; Zhang, 2003).

The diversification of the $\alpha_{2}$-adrenoreceptor genes in teleost fish deserves a special mention given that the last common ancestor of this group underwent an extra round of whole genome duplication in comparison to other vertebrates (Meyer and Van de Peer, 2005; Kasahara, 2007; Sato and Nishida, 2010). Given 
this, one could expect to find duplicated copies of all $\alpha_{2}$-adrenoreceptor gene lineages in teleost fish compared to the spotted gar, a holostean fish species that did not experience the extra round of whole genome duplication. In this case, special attention should be paid to synteny, given that the asymmetric loss of duplicates could cause one to misinterpret paralogy as orthology i.e. hidden paralogy (Daubin et al., 2001; Martin \& Burg, 2002; Kuraku, 2013; Kuraku et al., 2016). According to our phylogenetic tree, duplicated lineages were found in three (ADRA2A, ADRA2C and ADRA2D) out of four $\alpha_{2}$-adrenoreceptor genes (Fig. 4). In the case of ADRA2B, our phylogenetic analyses allowed us to identify one $\alpha_{2}$-adrenoreceptor gene lineage in nine species of teleost fish (Fig. 4). Synteny analyses provided extra support for the identity of this group of sequences as a gene lineage as we identified two genes upstream (GPAT2 and FAHD2A) and one downstream (DUSP2) that are conserved in most species. The presence of a single ADRA2B gene lineage in this group of teleost fish suggests that the loss of others occurred early in the evolutionary history of teleost fish.

\section{3. $\alpha_{2}$-adrenoreceptor polymorphisms in species related to humans}

Although there are several polymorphisms described for the $\alpha_{2}$-adrenoreceptor genes, in this work we only studied the variants that have been functionally characterized (Ahles and Engelhardt, 2014). Screening species closely related to humans could potentially shed light on the functional role of $\alpha_{2}$-adrenoreceptor gene variation. Especially important are the cases in which all closely related species possess the (alternative) allele that is associated with given pathological conditions in humans. This situation could indicate that the specific position of the allele itself does not produce the human pathological condition, rather pathology depends on the identity at other amino acid positions within the molecule (Breen et al., 2012; Natarayan et al., 2013).

In our survey, we compared polymorphisms that have been described and functionally characterized in humans in a panel of species that includes anthropoid primates and rodents (Table 1). We found that most examined 
species possess the most common alleles described for humans (Table 1).

There is also a group for which some species possess the most common allele, whereas others possess the alternative allele (Table 1). Additionally, we found one position for which the rare allele is present in all non-human species (Table 1 ), and there are some cases in which novel alleles are present (Table 1). The most interesting case is the polymorphism located approximately $70 \mathrm{~kb}$ (rs869244) downstream of the ADRA2A locus (Table 1). This polymorphism has been associated with platelet aggregation, a physiological response to vessel injury in response to three different agonists (ADP, epinephrine and collagen) (Johnson et al., 2010). Among humans and considering all human populations together, the alternative allele (adenine) is present at a frequency of $38 \%$; the frequency of this allele varies from $32 \%$ in African populations to $44 \%$ in South Asian populations (Kohler et al., 2014). According to our results, all non-human species possess the alternative allele (Table 1). Although it is possible that in non-human mammals the frequency of the minor allele follows the human trend, and we only screened individuals belonging to the $38 \%$ of the population, the fact that all examined species possess the alternative allele would suggest that adenine at this position is common in non-human mammalian species. If that were the case, our data would suggest that the specific position of the allele by itself potentially does not produce the human pathological condition; rather pathology depends on the identity at other positions.

The polymorphism described for the ADRA2C gene represents an inframe deletion of four amino acids (GlyAlaGlyPro), between positions 322 and 325 , in the third intracellular loop. Some studies have associated this polymorphism, in combination with the identity of position 389 (Arg) of the ADRB1 gene, with the risk for cardiovascular events (e.g. stroke, cardiac death) and early onset of hypertension (Small et al., 2002). However, there are other studies in which this association is unclear (Nonen et al., 2005; Metra et al., 2006; Canham et al., 2007). In our study, we found that all examined Old World monkeys (vervet, olive baboon, and macaque) possess the alternative allele, i.e a deletion of four amino acids (Table 1), suggesting that this variant could be 
common in this group of primates. Furthermore, according to Zavala et al. (2017), in Old World monkeys arginine at position 389 of the ADRB1 gene is also common. Thus, Old World monkeys possess both variants that have been associated with the risk of cardiovascular disease and early onset hypertension (Small et al., 2002). However, similarly to what was mentioned for the ADRA2A polymorphism, it is possible that genetic variants by themselves do not trigger the condition to which they have been linked; their effects could depend on the identity at other amino acid positions.

\section{Conclusions}

In this study, we present an evolutionary analysis of the $\alpha_{2}$-adrenoreceptor gene family in representative species of vertebrates. Our phylogenetic and synteny analyses show that in addition to the three well-recognized $\alpha_{2}$-adrenoreceptor genes (ADRA2A, ADRA2B and ADRA2C), we also recovered a clade that corresponds to the fourth member of the $\alpha_{2}$-adrenoreceptor gene family (ADRA2D). Based on the phyletic distribution of the genes, we show that all but two vertebrate groups retained the full complement of $\alpha_{2}$-adrenoreceptor genes; mammals and crocodiles are characterized by possessing three $\alpha_{2^{-}}$ adrenoreceptor family members. Furthermore, the $\alpha_{2 \mathrm{D}}$-adrenoreceptor could be a dispensable gene as it was lost two independent times during the evolutionary history of vertebrates. The pattern of differential retention observed for this group of genes opens new avenues to study the biology of the different $\alpha_{2-}$ adrenoreceptors. For example, mammals and crocodiles could be seen as natural knockout models for the $\alpha_{2 D}$-adrenoreceptor gene (ADRA2D). In addition to the above, studies of species that possess the full complement of $\alpha_{2}-$ adrenoreceptors (e.g. spotted gar) would provide significant evolutionary information regarding the division of labor in the $\alpha_{2}$-adrenoreceptor gene family. 


\section{Acknowledgments}

This work was funded by Fondo Nacional de Desarrollo Científico y Tecnológico (FONDECYT) grant 1160627 to JCO.

\section{Appendix A. Supplementary data}

Supplementary data associated with this article can be found in the online version. 


\section{Figure legends}

Figure 1. Maximum likelihood tree depicting evolutionary relationships among $\alpha_{2}$ adrenoreceptors. Numbers on the nodes correspond to maximum likelihood ultrafast bootstrap support values. Human ADRA1A, B, and D sequences were used as outgroups. Color dots denote the fish subtrees that are expanded in figure 4 .

Figure 2. Conserved synteny in the chromosomal regions that harbor $\alpha_{2}-$ adrenoreceptor genes. A) Chromosomal region that harbors ADRA2A genes; B) region that harbors the ADRA2B genes; C) Chromosomal region that harbors the ADR2C genes; D) Chromosomal region that harbors the ADR2D genes. Asterisks denote that the orientation of the genomic piece is from $3^{\prime}$ to $5^{\prime}$.

Figure 3. Phyletic distribution of $\alpha_{2}$-adrenoreceptor genes in gnathostomes.

Figure 4. Maximum likelihood trees depicting evolutionary relationships among $\alpha_{2}$-adrenoreceptors in fish. A) phylogenetic relationships among ADRA2A sequences; $B$ ) phylogenetic relationships among ADR2B sequences; $C$ ) phylogenetic relationships among $A D R A 2 C$ sequences; $D$ ) phylogenetic relationships among ADRA2D sequences. Numbers on the nodes correspond to maximum likelihood ultrafast bootstrap support values. These tree topologies do not represent novel phylogenetic analyses; they are the fish clades that were recovered from figure 1. 


\begin{tabular}{|c|c|c|c|c|c|c|c|}
\hline & \multicolumn{5}{|c|}{ ADRA2A } & ADRA2B & ADRA2C \\
\hline Position & -1252 & 798 & +427 & +69953 & +202941 & 901-909 & $964-975$ \\
\hline & & (266) & & & & $(301-303)$ & $(322-325)$ \\
\hline ID & rs1800544 & rs1800035 & rs553668 & rs869244 & rs10885122 & rs28365031 & rs61767072 \\
\hline $\begin{array}{l}\text { Common/rare } \\
\text { allele }\end{array}$ & $\mathrm{G} / \mathrm{C}$ & Asn/Lys & $A / G$ & $\mathrm{G} / \mathrm{A}$ & $T / G$ & GluGluGlu/del & GlyAlaGlyPro/del \\
\hline Human & G & Asn & A & G & $\mathrm{T}$ & GluGluGlu & GlyAlaGlyPro \\
\hline Chimpanzee & G & Asn & A & A & $T$ & GluGluGlu & GlyAlaGlyPro \\
\hline Gorilla & G & Asn & A & A & $\mathrm{T}$ & GluGluGlu & GlyAlaGlyPro \\
\hline Orangutan & G & Asn & N/A & N/A & $\mathrm{T}$ & GluGluGlu & GlyAlaGlyPro \\
\hline Vervet & G & Asn & $\mathrm{T}$ & A & $\mathrm{T}$ & GluGluGlu & Del \\
\hline Olive Baboon & G & Asn & $\mathrm{T}$ & A & $\mathrm{T}$ & GluGluGlu & Del \\
\hline Macaque & G & Asn & $\mathrm{T}$ & A & $\mathrm{T}$ & GluGlu- & Del \\
\hline Marmoset & G & Asn & $\mathrm{T}$ & A & $\mathrm{T}$ & GluGluGlu & $N / A$ \\
\hline Mouse & G & Asn & A & A & G & GluGluAsp & GlyProGly- \\
\hline
\end{tabular}




\section{References}

Ahles, A. and Engelhardt, S., 2014. Polymorphic variants of adrenoceptors: pharmacology, physiology, and role in disease. Pharmacol Rev 66, 598637.

Albalat, R. and Cañestro, C., 2016. Evolution by gene loss. Nat Rev Genet 17, 379-91.

Albertson, R.C., Cresko, W., Detrich, H.W. and Postlethwait, J.H., 2009. Evolutionary mutant models for human disease. Trends Genet 25, 74-81.

Altschul, S.F., Gish, W., Miller, W., Myers, E.W. and Lipman, D.J., 1990. Basic local alignment search tool. J Mol Biol 215, 403-10.

Blomme, T., Vandepoele, K., De Bodt, S., Simillion, C., Maere, S. and Van de Peer, Y., 2006. The gain and loss of genes during 600 million years of vertebrate evolution. Genome Biol 7, R43.

Bohmann, C., Schaible, U., Schollmeyer, P. and Rump, L.C., 1994. Alpha 2Dadrenoceptors modulate renal noradrenaline release in normotensive and spontaneously hypertensive rats. Eur J Pharmacol 271, 283-92.

Braidy, N., Poljak, A., Jayasena, T., Mansour, H., Inestrosa, N.C. and Sachdev, P.S., 2015. Accelerating Alzheimer's research through 'natural' animal models. Curr Opin Psychiatry 28, 155-64.

Brede, M., Nagy, G., Philipp, M., Sorensen, J.B., Lohse, M.J. and Hein, L., 2003. Differential control of adrenal and sympathetic catecholamine release by alpha 2-adrenoceptor subtypes. Mol Endocrinol 17, 1640-6.

Brede, M., Wiesmann, F., Jahns, R., Hadamek, K., Arnolt, C., Neubauer, S., Lohse, M.J. and Hein, L., 2002. Feedback inhibition of catecholamine release by two different alpha2-adrenoceptor subtypes prevents progression of heart failure. Circulation 106, 2491-6.

Breen, M.S., Kemena, C., Vlasov, P.K., Notredame, C. and Kondrashov, F.A., 2012. Epistasis as the primary factor in molecular evolution. Nature 490, 535-8.

Bylund, D.B., 1988. Subtypes of alpha 2-adrenoceptors: pharmacological and molecular biological evidence converge. Trends Pharmacol Sci 9, 356-61.

Bylund, D.B., 2005. Alpha-2 adrenoceptor subtypes: are more better? $\mathrm{Br} \mathrm{J}$ Pharmacol 144, 159-60.

Campanini, E.B., Vandewege, M.W., Pillai, N.E., Tay, B.H., Jones, J.L., Venkatesh, B. and Hoffmann, F.G., 2015. Early Evolution of Vertebrate Mybs: An Integrative Perspective Combining Synteny, Phylogenetic, and Gene Expression Analyses. Genome Biol Evol 7, 3009-21.

Canham, R.M., Das, S.R., Leonard, D., Abdullah, S.M., Mehta, S.K., Chung, A.K., Li, J.L., Victor, R.G., Auchus, R.J. and Drazner, M.H., 2007. Alpha2cDel322-325 and beta1Arg389 adrenergic polymorphisms are not associated with reduced left ventricular ejection fraction or increased left ventricular volume. J Am Coll Cardiol 49, 274-6.

Castro-Fuentes, R. and Socas-Pérez, R., 2013. Octodon degus: a strong attractor for Alzheimer research. Basic Clin Neurosci 4, 91-6.

Cañestro, C., Catchen, J.M., Rodríguez-Marí, A., Yokoi, H. and Postlethwait, J.H., 2009. Consequences of lineage-specific gene loss on functional 
evolution of surviving paralogs: ALDH1A and retinoic acid signaling in vertebrate genomes. PLoS Genet 5, e1000496.

Daubin, V., Gouy, M. and Perrière, G., 2001. Bacterial molecular phylogeny using supertree approach. Genome Inform 12, 155-64.

Dehal, P. and Boore, J.L., 2005. Two rounds of whole genome duplication in the ancestral vertebrate. PLoS Biol 3, e314.

Edrey, Y.H., Casper, D., Huchon, D., Mele, J., Gelfond, J.A., Kristan, D.M., Nevo, E. and Buffenstein, R., 2012. Sustained high levels of neuregulin-1 in the longest-lived rodents; a key determinant of rodent longevity. Aging Cell 11, 213-22.

Faulkes, C.G., Davies, K.T., Rossiter, S.J. and Bennett, N.C., 2015. Molecular evolution of the hyaluronan synthase 2 gene in mammals: implications for adaptations to the subterranean niche and cancer resistance. Biol Lett 11, 20150185.

Force, A., Lynch, M., Pickett, F.B., Amores, A., Yan, Y.L. and Postlethwait, J., 1999. Preservation of duplicate genes by complementary, degenerative mutations. Genetics 151, 1531-45.

Félix, M.A. and Barkoulas, M., 2015. Pervasive robustness in biological systems. Nat Rev Genet 16, 483-96.

Gabaldón, T., 2008. Large-scale assignment of orthology: back to phylogenetics? Genome Biol 9, 235.

Gabaldón, T. and Koonin, E.V., 2013. Functional and evolutionary implications of gene orthology. Nat Rev Genet 14, 360-6.

Gilsbach, R., Brede, M., Beetz, N., Moura, E., Muthig, V., Gerstner, C., Barreto, F., Neubauer, S., Vieira-Coelho, M.A. and Hein, L., 2007. Heterozygous alpha 2C-adrenoceptor-deficient mice develop heart failure after transverse aortic constriction. Cardiovasc Res 75, 728-37.

Gitelman, I., 2007. Evolution of the vertebrate twist family and synfunctionalization: a mechanism for differential gene loss through merging of expression domains. Mol Biol Evol 24, 1912-25.

Gorbunova, V., Hine, C., Tian, X., Ablaeva, J., Gudkov, A.V., Nevo, E. and Seluanov, A., 2012. Cancer resistance in the blind mole rat is mediated by concerted necrotic cell death mechanism. Proc Natl Acad Sci U S A 109, 19392-6.

Gribble, F.M., 2010. Alpha2A-adrenergic receptors and type 2 diabetes. N Engl J Med 362, 361-2.

Haubold, M., Gilsbach, R. and Hein, L., 2010. \{Alpha\}2B-adrenoceptor deficiency leads to postnatal respiratory failure in mice. J Biol Chem 285, 34213-9.

Henning, Y., Vole, C., Begall, S., Bens, M., Broecker-Preuss, M., Sahm, A., Szafranski, K., Burda, H. and Dammann, P., 2014. Unusual ratio between free thyroxine and free triiodothyronine in a long-lived mole-rat species with bimodal ageing. PLoS One 9, e113698.

Herrero, J., Muffato, M., Beal, K., Fitzgerald, S., Gordon, L., Pignatelli, M., Vilella, A.J., Searle, S.M., Amode, R., Brent, S., Spooner, W., Kulesha, E., Yates, A. and Flicek, P., 2016. Ensembl comparative genomics resources. Database (Oxford) 2016. 
Hoegg, S. and Meyer, A., 2005. Hox clusters as models for vertebrate genome evolution. Trends Genet 21, 421-4.

Hoffmann, F.G. and Opazo, J.C., 2011. Evolution of the Relaxin/Insulin-like Gene Family in Placental Mammals: Implications for Its Early Evolution. Journal of Molecular Evolution 72, 72-79.

Hoffmann, F.G., Opazo, J.C. and Storz, J.F., 2012. Whole-Genome Duplications Spurred the Functional Diversification of the Globin Gene Superfamily in Vertebrates. Molecular Biology and Evolution 29, 303-312.

Hughes, A.L., 1994. The evolution of functionally novel proteins after gene duplication. Proc Biol Sci 256, 119-24.

Inestrosa, N.C., Ríos, J.A., Cisternas, P., Tapia-Rojas, C., Rivera, S., D., Braidy, N., Zolezzi, J.M., Godoy, J.A., Carvajal, F.J., Ardiles, A.O., Bozinovic, F., Palacios, A.G. and Sachdev, P.S., 2015. Age Progression of Neuropathological Markers in the Brain of the Chilean Rodent Octodon degus, a Natural Model of Alzheimer's Disease. Brain Pathology doi: 10.1111/bpa.12226.

Kasahara, M., 2007. The 2R hypothesis: an update. Curr Opin Immunol 19, 54752.

Katoh, K. and Standley, D.M., 2013. MAFFT multiple sequence alignment software version 7: improvements in performance and usability. Mol Biol Evol 30, 772-80.

Knaus, A.E., Muthig, V., Schickinger, S., Moura, E., Beetz, N., Gilsbach, R. and Hein, L., 2007. Alpha2-adrenoceptor subtypes--unexpected functions for receptors and ligands derived from gene-targeted mouse models. Neurochem Int 51, 277-81.

Kobayashi, T., Matsumoto, T., Ooishi, K. and Kamata, K., 2004. Differential expression of alpha2D-adrenoceptor and eNOS in aortas from early and later stages of diabetes in Goto-Kakizaki rats. Am J Physiol Heart Circ Physiol 287, H135-43.

Kuraku, S., 2013. Impact of asymmetric gene repertoire between cyclostomes and gnathostomes. Semin Cell Dev Biol 24, 119-27.

Kuraku, S., Feiner, N., Keeley, S.D. and Hara, Y., 2016. Incorporating treethinking and evolutionary time scale into developmental biology. Dev Growth Differ 58, 131-42.

Köhler, S., Doelken, S.C., Mungall, C.J., Bauer, S., Firth, H.V., Bailleul-Forestier, I., Black, G.C., Brown, D.L., Brudno, M., Campbell, J., FitzPatrick, D.R., Eppig, J.T., Jackson, A.P., Freson, K., Girdea, M., Helbig, I., Hurst, J.A., Jähn, J., Jackson, L.G., Kelly, A.M., Ledbetter, D.H., Mansour, S., Martin, C.L., Moss, C., Mumford, A., Ouwehand, W.H., Park, S.M., Riggs, E.R., Scott, R.H., Sisodiya, S., Van Vooren, S., Wapner, R.J., Wilkie, A.O., Wright, C.F., Vulto-van Silfhout, A.T., de Leeuw, N., de Vries, B.B., Washingthon, N.L., Smith, C.L., Westerfield, M., Schofield, P., Ruef, B.J., Gkoutos, G.V., Haendel, M., Smedley, D., Lewis, S.E. and Robinson, P.N., 2014. The Human Phenotype Ontology project: linking molecular biology and disease through phenotype data. Nucleic Acids Res 42, D966-74. 
Lakhlani, P.P., MacMillan, L.B., Guo, T.Z., McCool, B.A., Lovinger, D.M., Maze, M. and Limbird, L.E., 1997. Substitution of a mutant alpha2a-adrenergic receptor via \&quot; hit and run\&quot; gene targeting reveals the role of this subtype in sedative, analgesic, and anesthetic-sparing responses in vivo. Proc Natl Acad Sci U S A 94, 9950-5.

Lanier, S.M., Downing, S., Duzic, E. and Homcy, C.J., 1991. Isolation of rat genomic clones encoding subtypes of the alpha 2-adrenergic receptor. Identification of a unique receptor subtype. J Biol Chem 266, 10470-8.

Link, R., Daunt, D., Barsh, G., Chruscinski, A. and Kobilka, B., 1992. Cloning of two mouse genes encoding alpha 2-adrenergic receptor subtypes and identification of a single amino acid in the mouse alpha 2-C10 homolog responsible for an interspecies variation in antagonist binding. Mol Pharmacol 42, 16-27.

Link, R.E., Desai, K., Hein, L., Stevens, M.E., Chruscinski, A., Bernstein, D., Barsh, G.S. and Kobilka, B.K., 1996. Cardiovascular regulation in mice lacking alpha2-adrenergic receptor subtypes b and c. Science 273, 803-5.

Louis, A., Nguyen, N.T., Muffato, M. and Roest Crollius, H., 2015. Genomicus update 2015: KaryoView and MatrixView provide a genome-wide perspective to multispecies comparative genomics. Nucleic Acids Res 43, D682-9.

MacMillan, L.B., Hein, L., Smith, M.S., Piascik, M.T. and Limbird, L.E., 1996. Central hypotensive effects of the alpha2a-adrenergic receptor subtype. Science 273, 801-3.

Manov, I., Hirsh, M., lancu, T.C., Malik, A., Sotnichenko, N., Band, M., Avivi, A. and Shams, I., 2013. Pronounced cancer resistance in a subterranean rodent, the blind mole-rat, Spalax: in vivo and in vitro evidence. BMC Biol $11,91$.

Martin, A.P. and Burg, T.M., 2002. Perils of paralogy: using HSP70 genes for inferring organismal phylogenies. Syst Biol 51, 570-87.

McLysaght, A., Hokamp, K. and Wolfe, K.H., 2002. Extensive genomic duplication during early chordate evolution. Nat Genet 31, 200-4.

Mehta, T.K., Ravi, V., Yamasaki, S., Lee, A.P., Lian, M.M., Tay, B.H., Tohari, S., Yanai, S., Tay, A., Brenner, S. and Venkatesh, B., 2013. Evidence for at least six Hox clusters in the Japanese lamprey (Lethenteron japonicum). Proc Natl Acad Sci U S A 110, 16044-9.

Metra, M., Zani, C., Covolo, L., Nodari, S., Pezzali, N., Gelatti, U., Donato, F., Nardi, G. and Dei Cas, L., 2006. Role of beta1- and alpha2c-adrenergic receptor polymorphisms and their combination in heart failure: a casecontrol study. Eur J Heart Fail 8, 131-5.

Meyer, A. and Schartl, M., 1999. Gene and genome duplications in vertebrates: the one-to-four (-to-eight in fish) rule and the evolution of novel gene functions. Curr Opin Cell Biol 11, 699-704.

Meyer, A. and Van de Peer, Y., 2005. From 2R to 3R: evidence for a fish-specific genome duplication (FSGD). Bioessays 27, 937-45.

Muthig, V., Gilsbach, R., Haubold, M., Philipp, M., Ivacevic, T., Gessler, M. and Hein, L., 2007. Upregulation of soluble vascular endothelial growth factor 
receptor 1 contributes to angiogenesis defects in the placenta of alpha 2Badrenoceptor deficient mice. Circ Res 101, 682-91.

Nah, G.S., Tay, B.H., Brenner, S., Osato, M. and Venkatesh, B., 2014.

Characterization of the Runx gene family in a jawless vertebrate, the Japanese lamprey (Lethenteron japonicum). PLoS One 9, e113445.

Natarajan, C., Inoguchi, N., Weber, R.E., Fago, A., Moriyama, H. and Storz, J.F., 2013. Epistasis among adaptive mutations in deer mouse hemoglobin. Science 340, 1324-7.

Niederhoffer, N., Hein, L. and Starke, K., 2004. Modulation of the baroreceptor reflex by alpha 2A-adrenoceptors: a study in alpha $2 \mathrm{~A}$ knockout mice. $\mathrm{Br} \mathrm{J}$ Pharmacol 141, 851-9.

Nonen, S., Okamoto, H., Akino, M., Matsui, Y., Fujio, Y., Yoshiyama, M., Takemoto, Y., Yoshikawa, J., Azuma, J. and Kitabatake, A., 2005. No positive association between adrenergic receptor variants of alpha2cDel322-325, beta1Ser49, beta1Arg389 and the risk for heart failure in the Japanese population. Br J Clin Pharmacol 60, 414-7.

Ohno, S., 1970. Evolution by gene duplication, Springer-Verlag.

Ohno, S., Wolf, U. and Atkin, N.B., 1968. Evolution from fish to mammals by gene duplication. Hereditas 59, 169-87.

Opazo, J.C., Lee, A.P., Hoffmann, F.G., Toloza-Villalobos, J., Burmester, T., Venkatesh, B. and Storz, J.F., 2015. Ancient Duplications and Expression Divergence in the Globin Gene Superfamily of Vertebrates: Insights from the Elephant Shark Genome and Transcriptome. Mol Biol Evol 32, 168494.

Opazo, J.C., Palma, R.E., Melo, F. and Lessa, E.P., 2005. Adaptive evolution of the insulin gene in caviomorph rodents. Mol Biol Evol 22, 1290-8.

Philipp, M., Brede, M.E., Hadamek, K., Gessler, M., Lohse, M.J. and Hein, L., 2002. Placental alpha(2)-adrenoceptors control vascular development at the interface between mother and embryo. Nat Genet 31, 311-5.

Putnam, N.H., Butts, T., Ferrier, D.E., Furlong, R.F., Hellsten, U., Kawashima, T., Robinson-Rechavi, M., Shoguchi, E., Terry, A., Yu, J.K., Benito-Gutiérrez, E.L., Dubchak, I., Garcia-Fernàndez, J., Gibson-Brown, J.J., Grigoriev, I.V., Horton, A.C., de Jong, P.J., Jurka, J., Kapitonov, V.V., Kohara, Y., Kuroki, Y., Lindquist, E., Lucas, S., Osoegawa, K., Pennacchio, L.A., Salamov, A.A., Satou, Y., Sauka-Spengler, T., Schmutz, J., Shin-I, T., Toyoda, A., Bronner-Fraser, M., Fujiyama, A., Holland, L.Z., Holland, P.W., Satoh, N. and Rokhsar, D.S., 2008. The amphioxus genome and the evolution of the chordate karyotype. Nature 453, 1064-71.

Qiu, H., Hildebrand, F., Kuraku, S. and Meyer, A., 2011. Unresolved orthology and peculiar coding sequence properties of lamprey genes: the KCNA gene family as test case. BMC Genomics 12, 325.

Ronquist, F. and Huelsenbeck, J.P., 2003. MrBayes 3: Bayesian phylogenetic inference under mixed models. Bioinformatics 19, 1572-1574.

Rosengren, A.H., Jokubka, R., Tojjar, D., Granhall, C., Hansson, O., Li, D.Q., Nagaraj, V., Reinbothe, T.M., Tuncel, J., Eliasson, L., Groop, L., Rorsman, P., Salehi, A., Lyssenko, V., Luthman, H. and Renström, E., 2010. 
Overexpression of alpha2A-adrenergic receptors contributes to type 2 diabetes. Science 327, 217-20.

Sato, Y. and Nishida, M., 2010. Teleost fish with specific genome duplication as unique models of vertebrate evolution. Environmental Biology of Fishes 88, 169-188.

Singh, P.P., Arora, J. and Isambert, H., 2015. Identification of Ohnolog Genes Originating from Whole Genome Duplication in Early Vertebrates, Based on Synteny Comparison across Multiple Genomes. PLoS Comput Biol 11, e1004394.

Small, K.M., Wagoner, L.E., Levin, A.M., Kardia, S.L. and Liggett, S.B., 2002. Synergistic polymorphisms of beta1- and alpha2C-adrenergic receptors and the risk of congestive heart failure. N Engl J Med 347, 1135-42.

Smith, J.J., Kuraku, S., Holt, C., Sauka-Spengler, T., Jiang, N., Campbell, M.S., Yandell, M.D., Manousaki, T., Meyer, A., Bloom, O.E., Morgan, J.R., Buxbaum, J.D., Sachidanandam, R., Sims, C., Garruss, A.S., Cook, M., Krumlauf, R., Wiedemann, L.M., Sower, S.A., Decatur, W.A., Hall, J.A., Amemiya, C.T., Saha, N.R., Buckley, K.M., Rast, J.P., Das, S., Hirano, M., McCurley, N., Guo, P., Rohner, N., Tabin, C.J., Piccinelli, P., Elgar, G., Ruffier, M., Aken, B.L., Searle, S.M., Muffato, M., Pignatelli, M., Herrero, J., Jones, M., Brown, C.T., Chung-Davidson, Y.W., Nanlohy, K.G., Libants, S.V., Yeh, C.Y., McCauley, D.W., Langeland, J.A., Pancer, Z., Fritzsch, B., de Jong, P.J., Zhu, B., Fulton, L.L., Theising, B., Flicek, P., Bronner, M.E., Warren, W.C., Clifton, S.W., Wilson, R.K. and Li, W., 2013. Sequencing of the sea lamprey (Petromyzon marinus) genome provides insights into vertebrate evolution. Nat Genet 45, 415-21, 421e1-2.

Spielman, S.J., Kumar, K. and Wilke, C.O., 2015. Comprehensive, structurallyinformed alignment and phylogeny of vertebrate biogenic amine receptors. PeerJ 3, e773.

Storz, J.F., Opazo, J.C. and Hoffmann, F.G., 2013. Gene duplication, genome duplication, and the functional diversification of vertebrate globins. Mol Phylogenet Evol 66, 469-78.

Trifinopoulos, J., Nguyen, L.T., von Haeseler, A. and Minh, B.Q., 2016. W-IQTREE: a fast online phylogenetic tool for maximum likelihood analysis. Nucleic Acids Res 44, W232-5.

Wichmann, I.A., Zavala, K., Hoffmann, F.G., Vandewege, M.W., Corvalán, A.H., Amigo, J.D., Owen, G.I. and Opazo, J.C., 2016. Evolutionary history of the reprimo tumor suppressor gene family in vertebrates with a description of a new reprimo gene lineage. BMC Genomics Accepted.

Yu, C., Li, Y., Holmes, A., Szafranski, K., Faulkes, C.G., Coen, C.W., Buffenstein, R., Platzer, M., de Magalhães, J.P. and Church, G.M., 2011. RNA sequencing reveals differential expression of mitochondrial and oxidation reduction genes in the long-lived naked mole-rat when compared to mice. PLoS One 6, e26729.

Zavala, K., Vandewege, M.W., Hoffmann, F.G. and Opazo, J.C., 2017. Evolution of the $\beta$-adrenoreceptors in vertebrates. Gen Comp Endocrinol 240, 129137. 
bioRxiv preprint doi: https://doi.org/10.1101/106526; this version posted February 7, 2017. The copyright holder for this preprint (which was not certified by peer review) is the author/funder, who has granted bioRxiv a license to display the preprint in perpetuity. It is made available under aCC-BY-NC-ND 4.0 International license.

Zhang, J., 2003. Evolution by gene duplication: An update. Trends in Ecology and Evolution 18, 292-298 

certified by peer review) is the author/funder, who has granted bioRxiv a license to display the preprint in perpetuity. It is made available under

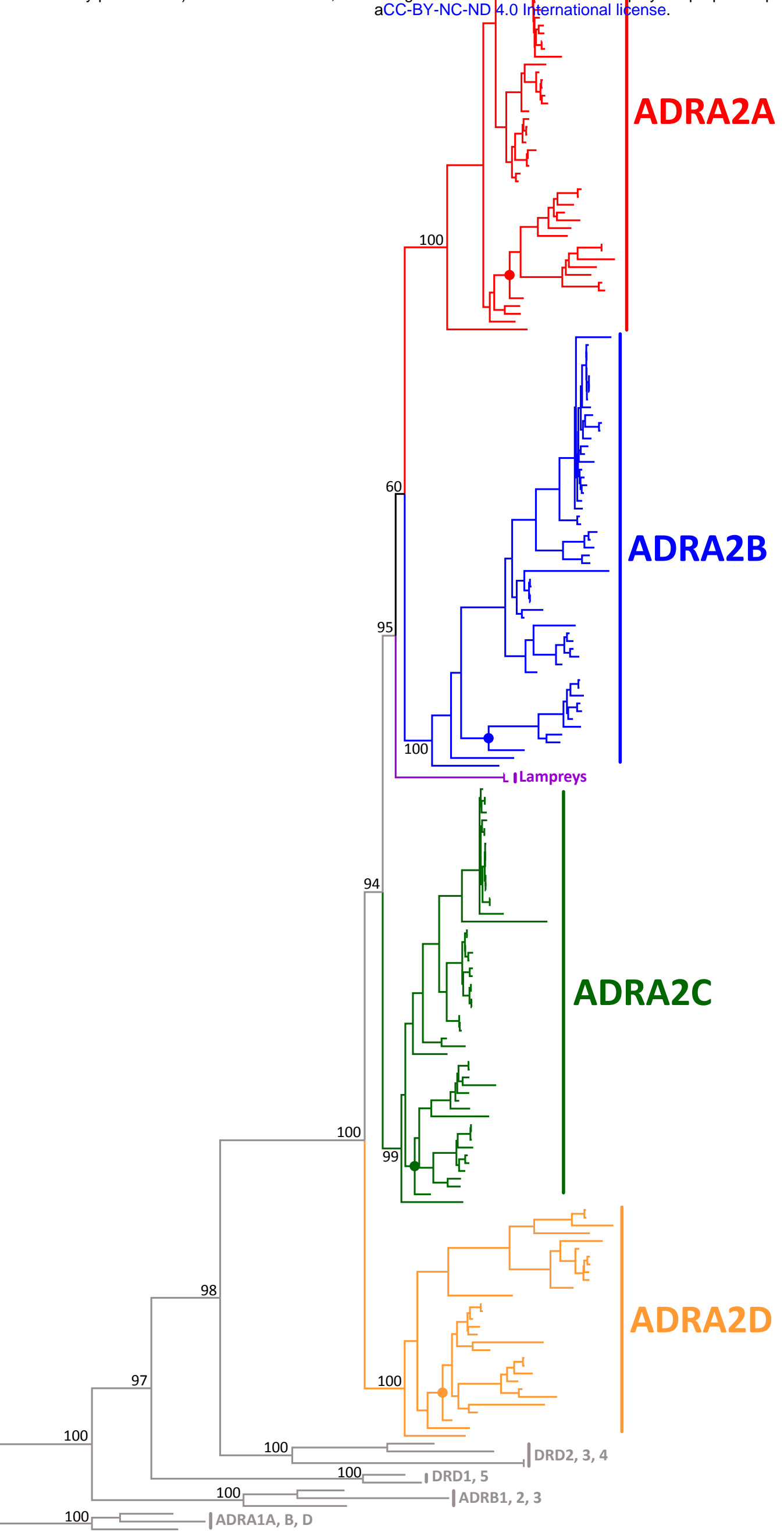


bioRxiv preprint doi: https://doigo org/10.1101/dु 6526 ; this vension posted February 7, 2017. The copyright holder for this preprint (which was not certified by peer review) is the author/funder, who has grented bioRxiv license to display the preprist in perpetuity. It is made available under

A)

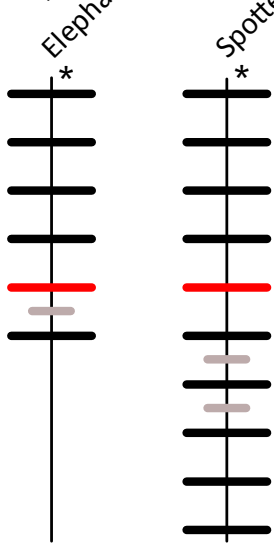

aCQ 28 Y-NC-ND 4 s Internationaticense.

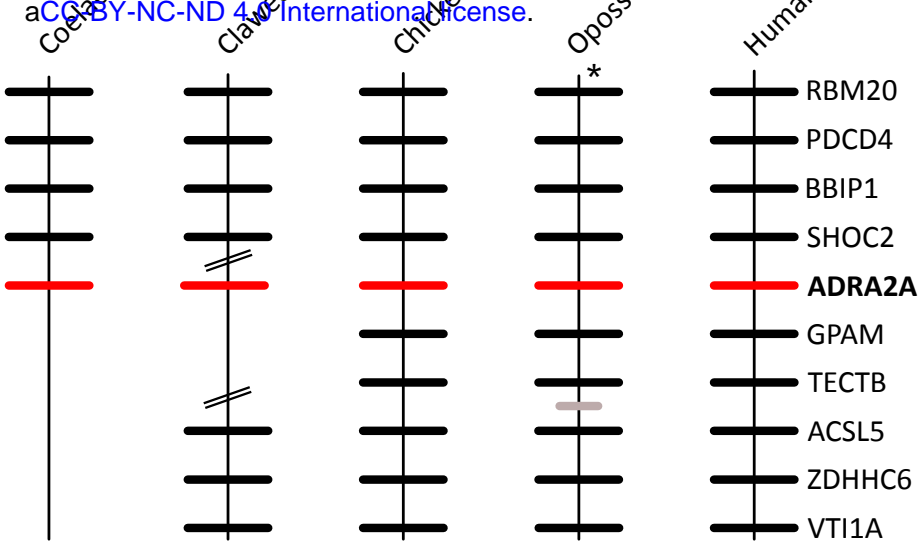

B)
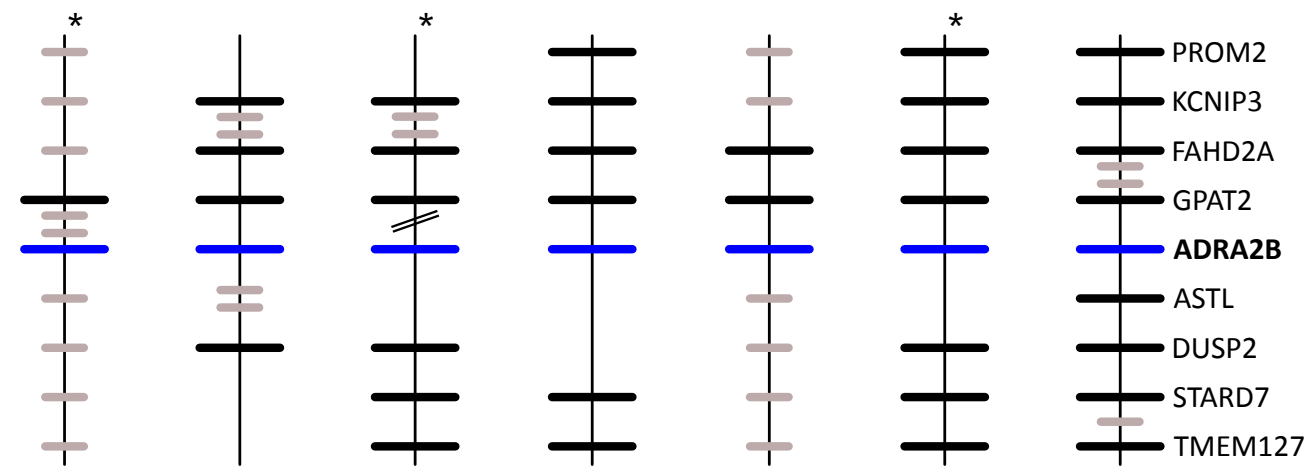

C)
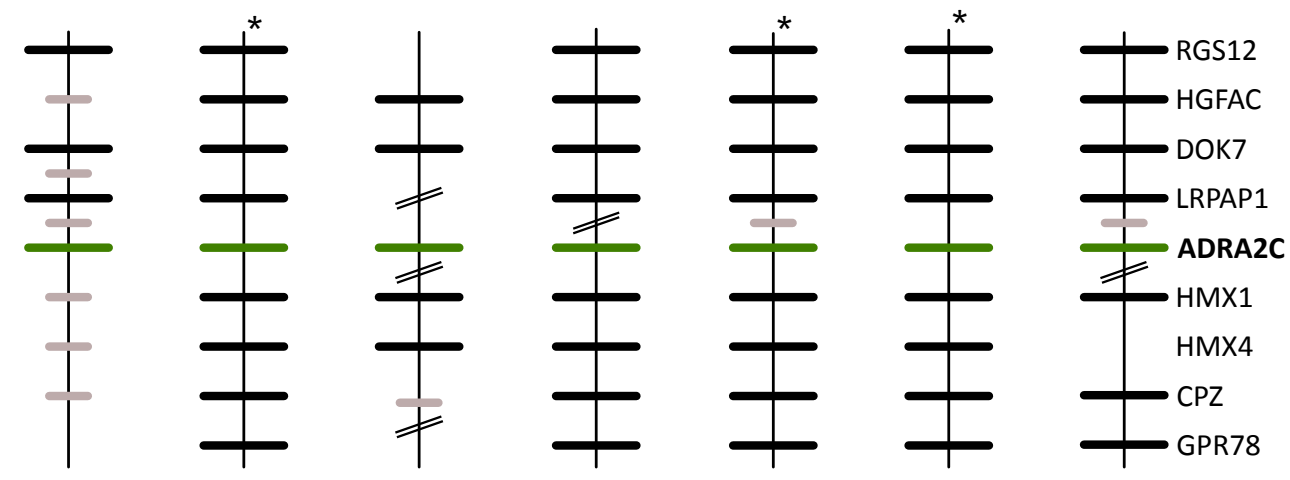

D)
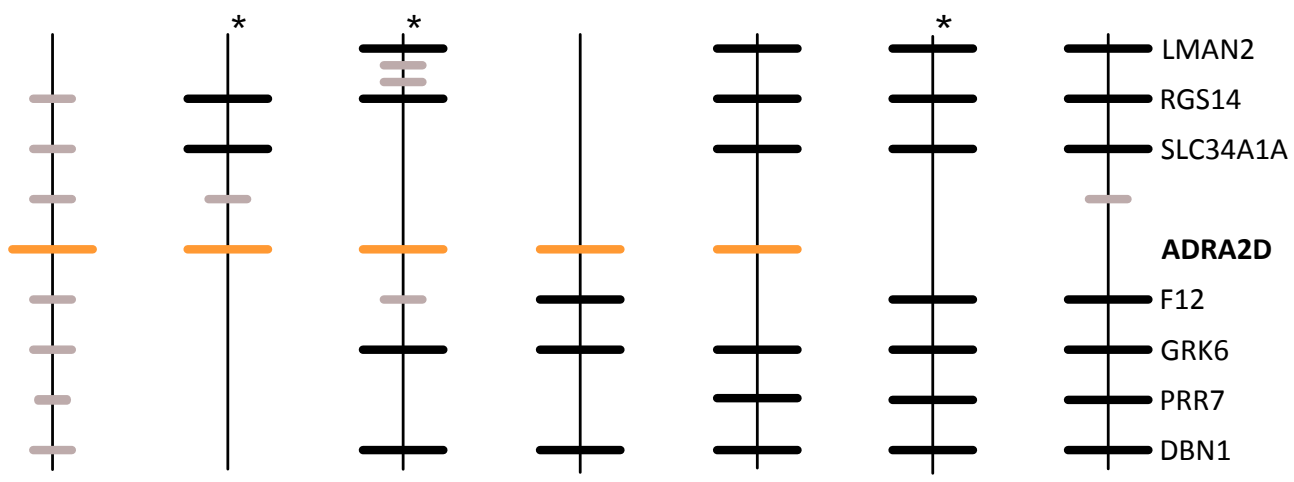


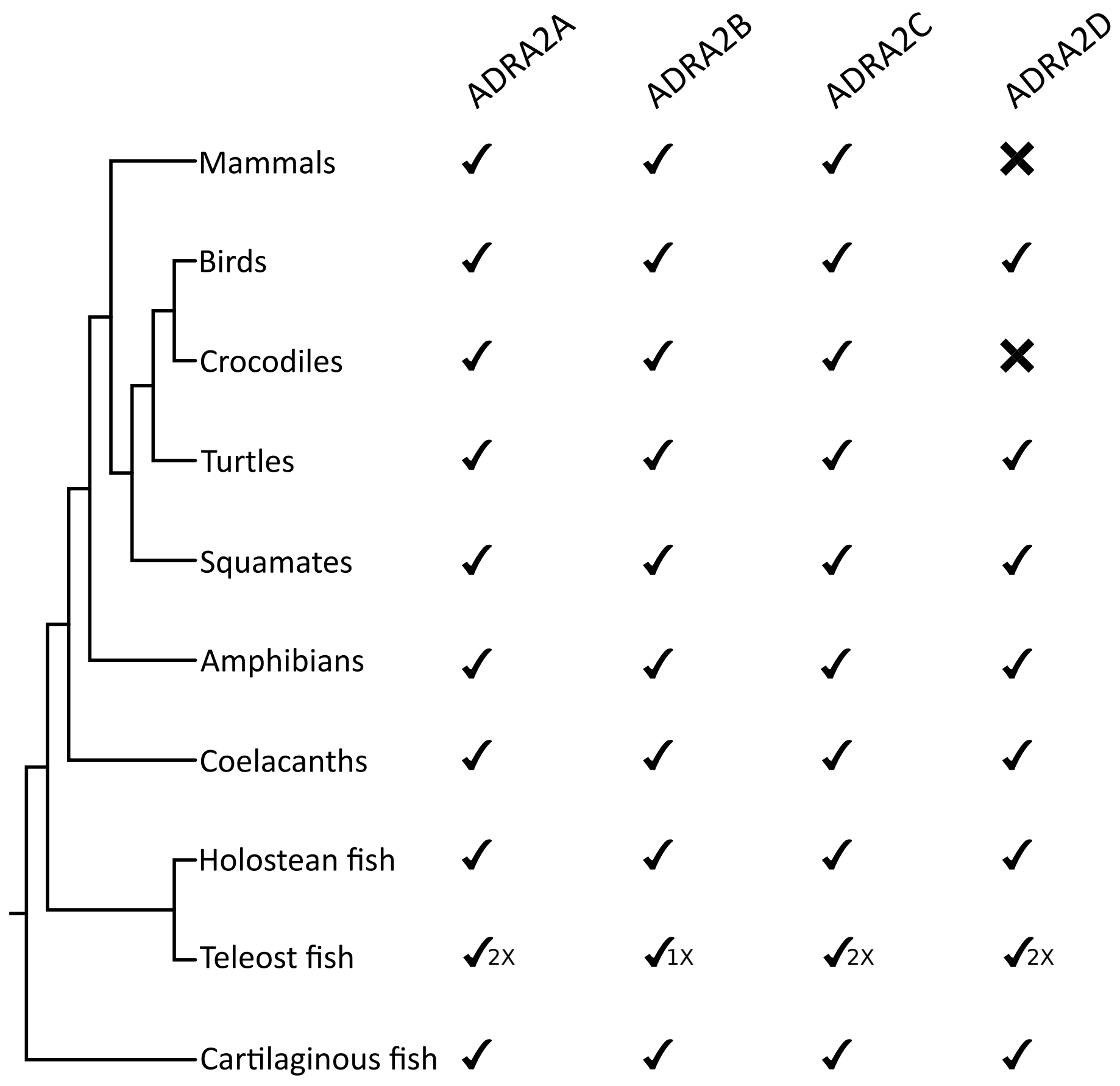


bioRxiv preprint doi: https://doi.org/10.1101/106526; thispersionpgsted February 7, 2017. The copyright holder for this preprint (which was not

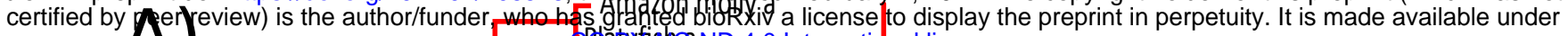

A)

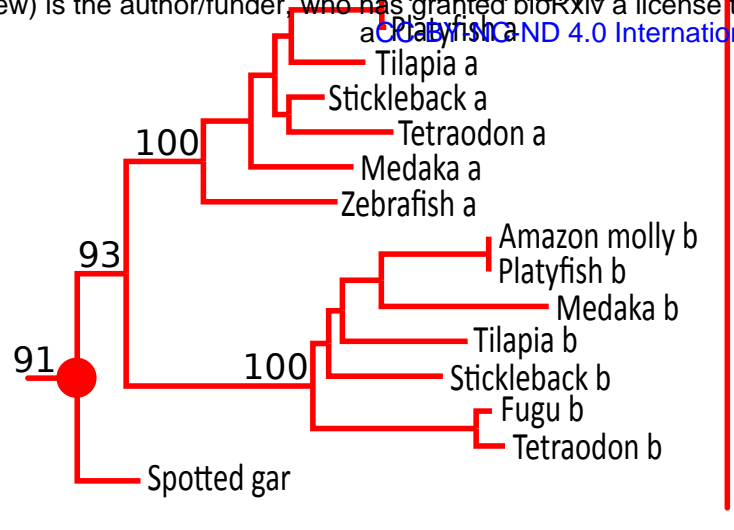

\section{0}

B)

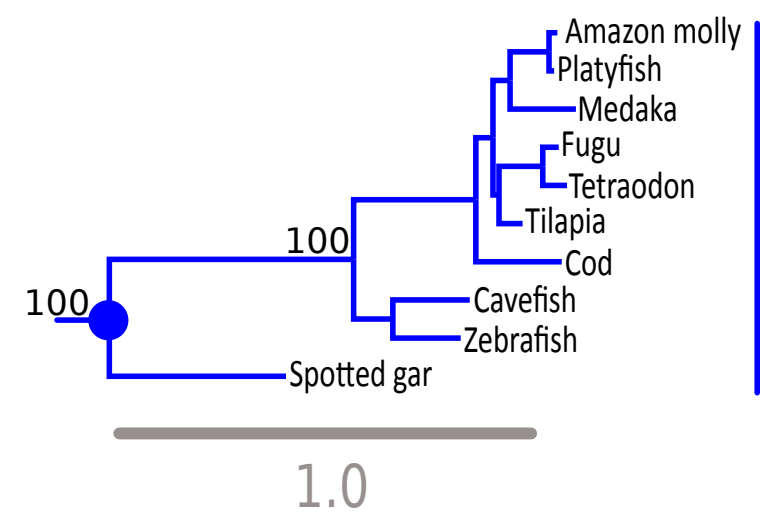

ADRA2B
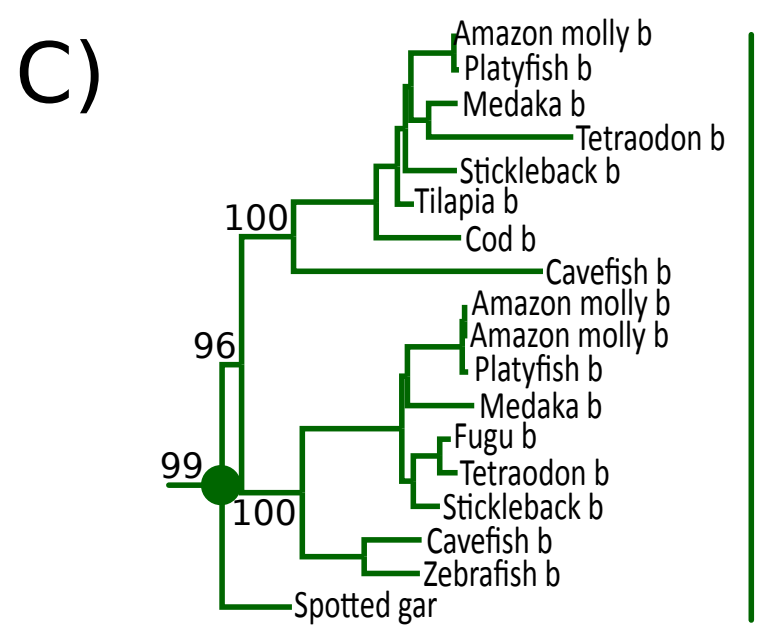

ADRA2C

D)

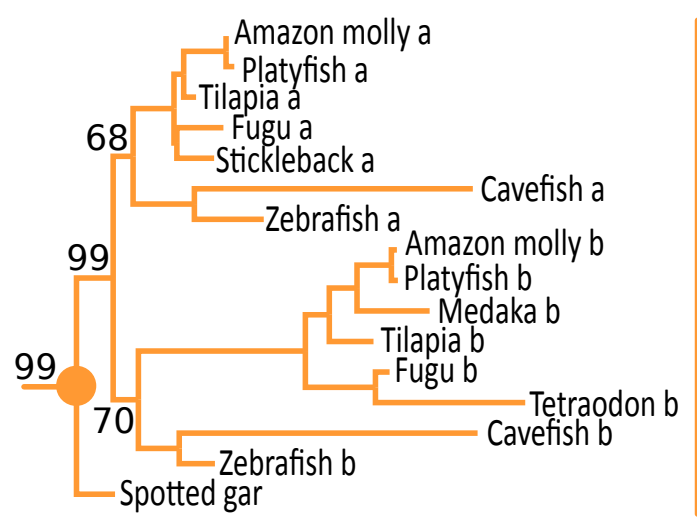

